
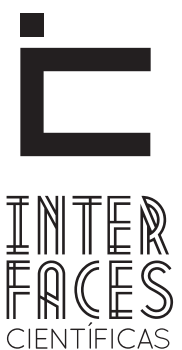

DIREITO

\title{
A MEDIAÇÃO COMO DIREITO FUNDAMENTAL E ACESSO À JUSTIÇA
}

\author{
MEDIATION AS A FUNDAMENTAL RIGHT AND ACCESS TO JUSTICE
}

LA MEDIACIÓN COMO DERECHO FUNDAMENTAL Y ACCESO A LA JUSTICIA

Natália Pereira Dalto ${ }^{1}$

\section{RESUMO}

O presente trabalho visa refletir sobre uma prática ainda pouco utilizada no Brasil como meio de resolução de conflitos e que pode auxiliar na construção de uma sociedade mais consciente de seus direitos humanos, onde os cidadãos possam vivenciar a justiça e a democracia. A mediação como direito humano fundamental e acesso à justiça onde o cidadão através do próprio empoderamento tem a oportunidade de resolver seus conflitos através de técnicas desenvolvidas por um terceiro imparcial e escolhida pelas partes. $\mathrm{O}$ acesso à justiça é direito humano e essencial ao completo exercício da cidadania. Mais que acesso ao judiciário, alcança também o acesso a aconselhamento, mediação, conciliação, consultoria, enfim, justiça social, orientando as partes a alcançarem a resolução de seus conflitos. Precisa-se destacar, entretanto, que o acesso à justiça, garantido pela Carta Magna, é um direito e, não, um dever do cidadão de provocar o Poder Judiciário para debelar todos os conflitos de interesses surgidos das interações entre os indivíduos na sociedade. Estabelecida essa premissa, impõe-se uma mudança de cultura dos sujeitos de direito objetivando prestigiar os métodos auto compositivos, como a mediação e a conciliação, como meios adequados para se dirimir os conflitos de interesses no Estado Democrático de Direito. Este artigo tem objetivo de contribuir para a formação de estudantes e pesquisadores pela justiça e equidade social. 


\section{PALAVRAS CHAVE}

Mediação; Direitos Humanos e Justiça Social

\section{ABSTRACT}

This paper aims to reflect on a practice still little used in Brazil as a means of resolving conflicts and that can help in the construction of a society more aware of its human rights, where citizens can experience justice and democracy. Mediation as a fundamental human right and access to justice where citizens through their own empowerment have the opportunity to resolve their conflicts through techniques developed by an impartial third party and chosen by the parties. Access to justice is a human right and essential to the full exercise of citizenship. More than access to the judiciary, it also reaches access to counseling, mediation, conciliation, counseling, and finally, social justice, guiding the parties to resolve their conflicts. It should be emphasized, however, that access to justice, guaranteed by the Constitution, is a right and not a duty of the citizen to provoke the Judiciary to dispel all conflicts of interest arising from the interactions between individuals in society. Once this premise has been established, it is necessary to change the culture of the subjects of law, with a view to emphasizing self-compositional methods, such as mediation and conciliation, as adequate means to resolve conflicts of interest in the Democratic State of Law. This article aims to contribute to the training of students and researchers for justice and social equity.

\section{KEYWORDS}

\author{
Mediation. Human Right. Social Justice
}

\section{RESUMEN}

El presente trabajo pretende reflexionar sobre una práctica aún poco utilizada en Brasil como medio de resolución de conflictos y que puede auxiliar en la construcción de una sociedad más consciente de sus derechos humanos, donde los ciudadanos puedan vivir la justicia y la democracia. La mediación como derecho humano fundamental y acceso a la justicia donde el ciudadano a través del propio empoderamiento tiene la oportunidad de resolver sus conflictos a través de técnicas desarrolladas por un tercer imparcial y escogida por las partes. El acceso a la justicia es un derecho humano y esencial para el pleno ejercicio de la ciudadanía. Más que acceso al poder judicial, alcanza también el acceso a asesoramiento, mediación, conciliación, consultoría, en fin, justicia social, orientando a las partes a alcanzar la resolución de sus conflictos. Se debe destacar, sin embargo, que el acceso a la justicia, garantizado por la Carta Magna, es un derecho y no un deber del ciudadano de provocar el Poder Judicial para resolver todos los conflictos de intereses surgidos de las interacciones entre los individuos en la sociedad. Establecida esta premisa, se impone un cambio de cultura de los sujetos de derecho con el objetivo de prestigiar los métodos autocompositivos, como la mediación y la conciliación, como medios adecuados para dirimir los conflictos de intereses en el Estado Democrático de Derecho. Este artículo tiene el objetivo de contribuir a la formación de estudiantes e investigadores por la justicia y la equidad social. 


\section{PALABRAS CLAVE}

Mediación; Derechos Humanos y Justicia Social

\section{INTRODUÇÃO}

0 acesso à justiça está previsto no artigo $5^{\circ}, \mathrm{XXXV}$ da Constituição Federal que diz: "a lei não excluirá da apreciação do Poder Judiciária lesão ou ameaça de direito". Pode ser chamado também de princípio da inafastabilidade do controle jurisdicional ou princípio do direito de ação. Tratamos aqui de um direito humano e essencial ao completo exercício da cidadania. Mais que acesso ao judiciário, alcança também o acesso a aconselhamento, mediação, conciliação, consultoria, enfim, justiça social, orientando as partes a alcançarem a resolução de seus conflitos.

0 disposto no artigo $5^{\circ}$, XXXV, da Constituição $\mathrm{Fe}$ deral é muito mais abrangente que o acesso ao Poder Judiciário e suas instituições por lesão a direito. Vai além, enquadrando-se aí também a ameaça de direito, e segue-se com uma enorme gama de valores e direitos fundamentais do ser humano.

Segundo Marmelstein (2014), a expressão: todos são iguais perante a lei, sem distinção de qualquer natureza enuncia um dever ético-jurídico de respeito ao outro. Esse dever base da dignidade da pessoa humana se materializa juridicamente por meio dos mandamentos constitucionais de não discriminação, de tolerância, de respeito às diferenças e de combate ao preconceito e ao racismo.

0 preâmbulo da constituição faz menção à sociedade fraterna, pluralista e sem preconceito. 0 art. $3^{\circ}$, inc.IV, inclui como objetivo da República Federativa do Brasil "a promoção do bem de todos, sem preconceito de origem, raça, cor, sexo, idade e quaisquer outras formas de discriminação". 0 art. $5^{\text {a determina }}$ que "homens e mulheres são iguais em direitos e obrigações, nos termos desta constituição" (inc.1). E mais à frente (inc. XLII) estabelece que a prática do racismo constitui crime inafiançável, sujeito a pena de reclusão nos termos da lei".

Segundo Marmelstein (2014), há ainda dentro do art. $5^{\circ}$, uma proteção implícita à autonomia da vontade, aqui entendida como a faculdade que o indivíduo possui para tomar decisões na sua esfera particular de acordo com seus próprios interesses e preferências. Isso significa basicamente o reconhecimento do direito individual de fazer tudo aquilo que se tem vontade, desde que não prejudique os interesses de outras pessoas. Cada um deve ser senhor de si, agindo como um ser responsável por suas próprias escolhas pessoais, especialmente por aquelas que não interferem na liberdade alheia.

Portanto, pretende-se com este trabalho discutir e refletir sobre uma prática ainda pouco utilizada no Brasil como meio de resolução de conflitos e que pode auxiliar na construção de uma sociedade mais consciente de seus direitos humanos, onde os cidadãos possam vivenciar a justiça e a democracia. A mediação como direito humano fundamental e acesso à justiça onde o cidadão por seu empoderamento tem a oportunidade de resolver seus conflitos por meio de técnicas desenvolvidas por um terceiro imparcial e escolhida pelas partes.

\section{DIREITOS HUMANOS}

É comum identificar várias dimensões dos direitos humanos, para alguns até gerando certa classificação dos direitos. A doutrina costuma classificar os direitos fundamentais em gerações ou dimensões, sendo que 
a primeira dimensão abrange o direito à liberdade, à expressão, à locomoção e à vida, que surgiu entre os séculos XII e XIX.

0 primeiro documento que traz a instituição destes direitos é a Magna Carta de 1215, da Inglaterra, assinada pelo rei João Sem Terra. A segunda dimensão é formada pelos direitos sociais, culturais, econômicos, ramificações do direito à igualdade, impulsionados pela Revolução Industrial europeia. Os principais documentos que representam esta geração são a Constituição de Weimar, da Alemanha e o Tratado de Versales, ambos de 1919.

A terceira dimensão dos direitos fundamentaissurgeenglobando os direitos à paz, a uma qualidade de vida saudável, à proteção ao consumidor e à preservação do meio-ambiente. Introduzidos pela globalização política, a quarta dimensão é formada pelos direitos à democracia, à informação, ao pluralismo e de normatização do patrimônio genético. Não é unânime a aceitação desta geração de direitos fundamentais.

0 direito constitucional brasileiro tem avançado muito nos últimos anos. Em 1988 com o advento da Constituição Cidadã nossa então chamada Carta Magna, não tínhamos noção do avanço que poderíamos ter, nem tão pouco das transformações dogmáticas constitucionais que estamos vivendo.

Indubitavelmente, a expressão "direitos humanos "chega ao século XXI com grande força e vitalidade, sendo largamente utilizada em manifestações da sociedade civil, na política, para pleitear direitos, enfim, nas mais distintas reivindicações. Por outro lado, em razão do uso excessivo e por vezes indiscriminado dessa expressão, ela acaba por incorrer em certa vagueza e imprecisão. Como assevera Rey Pérez, "el término derechos humanos resulta problemático al menos por dois motivos: porque tiene diversas significaciones y porque además existen distintas palabras que quierenexpresarsu concepto. (GUERRA, 2013, p. 31).

Guerra (2013) chama atenção para a ausência do consenso quanto à terminologia mais adequado para refletir-se aos direitos humanos fundamentais, revelando ponto de vista favorável e contraditório ao emprego desses ou daqueles ramos. A própria Cons- tituição Brasileira de 1988 recorre a expressões semanticamente diversificadas para fazer alusão a tais direitos: direitos humanos (art. $\left.4^{\circ}, \mathrm{II}\right)$; direitos e garantias fundamentais (Titulo II e art. $5^{\circ}, \$ 1^{\circ}$ ); direitos e liberdades constitucionais (art.5०, LXXI); direitos e garantias individuais (art. 60, $\$ 4^{\circ}, \mathrm{IV}$ ).

De acordo com Nogueira (apud GUERRA, 2013, p.11):

[...] o emprego dessas expressões como sinônimas é incorreto e elas possuem unicamente um núcleo comum, que é a Liberdade: As expressões Direitos dos Homens, Direitos Fundamentais e Liberdades Públicas tem sido, equivocadamente, usada indistintamente como sinônimos. Em verdade guardam entre si, de rigor, apenas um núcleo comum, a liberdade.

Referido autor aponta várias conexões ou ângulos de abordagem relacionados ao estudo desse tema, citando vários autores que demonstram a questão. Verifica-se, por exemplo, o posicionamento de Blanca Martínez, que reserva a formula "direitos humanos" para aqueles positivados em nível internacional (exigência básica relacionada à igualdade, liberdade da pessoa, que não havia alcançado um estudo jurídico positivo) e "direitos fundamentais" para os direitos humanos positivados internamente, isto é, garantidos pelos ordenamentos jurídico-positivos estatais.

Os direitos humanos fundamentais, em sua concepção atualmente conhecida, surgiram como produto da fusão de várias fontes, desde tradições arrigadas nas diversas civilizações, até a conjugação dos pensamentos filosófico-jurídicos, das ideias surgidas com o cristianismo e com o direito natural (MORAES, 2013, p. 3).

A problemática do direito de acesso à justiça se fez perceber mais intensamente nos Estados liberais burgueses dos séculos XVIII e XIX. O embrião do direito ao acesso à justiça, porém, pode ser apreendido no período antigo, pois se visualizam no Código de Hamurabi as primeiras garantias que podem ser entendidas como inibidoras de opressão entre os indivíduos, bem como o incentivo a estes a procurarem a instância judicial, no caso, o próprio soberano (MORAES, 2013, p. 3). 
Nesse primeiro momento, o acesso à justiça estava umbilicalmente ligado ao acesso à religião, pois a justiça do soberano - representante da divindade na Terra ou, então, considerada a própria divindade emana da justiça divina e é realizada, por conseguinte, por meio de inspiração divina. Frise-se, ainda, que o estrangeiro e o escravo - que nesse período histórico em muitos momentos se confundiam - não são considerados indivíduos capazes de ter acesso à justiça (MORAES, 2013, p. 3).

\begin{abstract}
A expressão direitos humanos representa o conjunto das atividades realizadas de maneira consciente, com o objetivo de assegurar ao homem a dignidade e evitar que passe por sofrimentos. Esta é a opinião de Carlos Santiago Niño, no livro Ethics of Human Rights. Para chegar a esta concepção contemporânea, no entanto, o homem precisou percorrer um longo caminho de lutas, até entre irmãos, quase sempre causadas pelo desejo do lucro ou do poder. Por isso mesmo é que se tornou uma convenção moderna considerar que somente em nações democráticas é possível existirem os direitos humanos, porque um governo autoritário transforma-se muito facilmente em opressor. (CASTILHO, 2011, p.11).
\end{abstract}

No direito romano, por sua vez, havia primeiramente a justiça privada. Posteriormente, criou-se a figura do árbitro, o qual era escolhido pelas próprias partes litigantes para dirimir a controvérsia. A função de árbitro era geralmente atribuída a algum sacerdote, pois se tratava de pessoa imparcial e, além disso, traduzia a vontade divina. Ainda em Roma, inaugurou-se a figura do pretor, que elaborava a regra a ser aplicada no caso concreto e indicava um árbitro que iria decidir a controvérsia, função que em seguida passou a exercer cumulativamente (CASTILHO, 2011).

$\mathrm{Na}$ Idade Antiga, portanto, a figura do julgador passou do soberano, por todos os cidadãos, pelo sacerdote e chegou ao pretor, sendo neste último o início da justiça pública, isto é, da jurisdição. No período medieval havia forte influência da concepção religiosa em toda a sociedade, inclusive sobre o direito e a justiça. 0 indivíduo, nesse cenário, era julgado pela sua fé. Isso se deve ao predomínio da Igreja Católica após a queda do Império Romano, porquanto "[...] passou a ser a única instituição organizada e com a capacidade de produzir uma síntese do legado [...] da estrutura política [...]" do Império Romano, caracterizando-se como herdeira natural desse império. $\mathrm{Na}$ modernidade, sobretudo nos Estados liberais burgueses dos séculos XVIII e XIX, os procedimentos adotados para o tratamento de controvérsias refletiam a filosofia essencialmente individualizada dos direitos (CASTILHO, 2011).

Dessa forma, o acesso à justiça restringia-se ao direito formal do cidadão perante o Poder Judiciário de propor ou contestar uma ação. Enquanto o direito de acesso à justiça era consolidado na Europa (mesmo no período do sistema laissez-faire dos séculos XVIII e XIX), no Brasil andava a passos lentos. Do ponto de vista legislativo, havia pouquíssimas referências a um direito próprio e exigível de acesso à justiça.

As Ordenações Filipinas, do século XVII, restringiam-se a afirmar que às pessoas miseráveis era assegurado o patrocínio de advogado. Saliente-se que após a proclamação da Independência do Brasil em 1822, portanto já no século XIX, o direito ao acesso à justiça pouco havia sido modificado. A Constituição de 1824, embora estabelecesse a partir do artigo 151 as diretrizes do "Poder Judicial", prévia uma matriz fortemente centralizadora que concedia ao Imperador a cumulação do exercício do cargo de "Chefe do Poder Executivo" (arts. 102 a 104) e do "Poder Moderador" (arts. 10 e 98 a 101), o que impedia o pleno exercício do direito ao acesso à justiça.

Relativamente à legislação infraconstitucional desse período, ressalte-se que o Código de Processo Criminal de 1832 estabelecia disposições provisórias sobre a administração da justiça, inclusive no aspecto de processo civil, que posteriormente foram utilizadas como bases para o futuro Código de Processo Civil. Desse modo, em decorrência do processo histórico e político da época, é possível afirmar (MORAES, 2013, p. 3).

De acordo com a declaração Universal dos direitos humanos, os direitos humanos são para além de todos aqueles direitos considerados universais e inalienáveis, ou seja, é um conjunto mínimo de direitos necessários para assegurar uma vida ao ser humano 
baseado na liberdade e na dignidade. Um dos grandes desafios na sociedade contemporânea e a efetivação da dignidade da pessoa humana.

A dignidade da pessoa humana está fundada no conjunto de direitos inerentes à personalidade da pessoa (liberdade e igualdade) e também no conjunto de direitos estabelecidos para a coletividade (sociais, econômicos e culturais). Por isso, a dignidade da pessoa não admite discriminação, seja de nascimento, sexo, idade, opinião ou crença, classe social e outras (CASTILHO, 2011).

No caso dos EUA, o movimento de independência das treze colônias britânicas teve como motivos principais a conduta adotada pela Inglaterra nos anos antecedentes a luta pela separação política. A adoção de leis mercantilistas, favoráveis unicamente aos interesses da metrópole, as incessantes guerras em que a Inglaterra esteve envolvida com outras nações nas décadas passadas, além dos custos de manutenção das tropas britânicas instaladas nas colônias, sobre os quais estas estavam responsáveis, favoreceram o surgimento de um sentimento de independência entre os colonos.

Foi dentro desse contexto que foi escrita a Declaração de Virgínia. Expondo de forma resumida os direitos naturais dos homens, essa declaração escrita pelos congressistas do estado de Virgínia estabeleceu a proteção à vida, liberdade, propriedade e a procura pela felicidade dos indivíduos como essenciais a um governo que visa o bem comum. De certa forma essas declarações anteciparam em um mês o conteúdo da declaração de independência nacional. Aliás, é nítido o quanto essa declaração de direitos teve por base teórica as obras dos filósofos ingleses John Locke e Thomas Paine, este último tendo atuado diretamente no processo de independência.

Sobre a proteção dos direitos humanos, podemos destacar que o advento do Direito Internacional dos Direitos Humanos, em 1945, possibilitou o surgimento de uma nova forma de cidadania. Desde então, a proteção jurídica do sistema internacional ao ser humano passou a independer do seu vínculo de nacionalidade com um Estado específico, tendo como requisito único e fundamental o fato do nascimento.
Essa nova cidadania pode ser definida como cidadania mundial ou cosmopolita, diferenciando-se da cidadania do Estado-Nação. A cidadania cosmopolita é um dos principais limites para a atuação do poder soberano, pois dá garantia da proteção internacional na falta da proteção do Estado Nacional.

Cada homem vale pelo lugar onde está: o seu valor como produtor, consumidor, cidadão, depende de sua localização no território. Seu valor vai mudando, incessantemente, para melhor ou para pior, em função das diferenças de acessibilidade (tempo, frequência, preço), independentes de sua própria condição. Pessoas, com essas virtudes, formação e salários idênticos salários têm valores diferentes segundo o lugar em que vivem: as oportunidades não são as mesmas. Por isso, a possibilidade de ser mais ou menos cidadão depende, em larga proporção, do ponto do território onde se está. Enquanto um lugar vem a ser condição de sua pobreza, outro lugar poderia, no mesmo momento histórico, facilitar o acesso àqueles bem e serviços que lhe são teoricamente devidos, mas que, de fato, lhe faltam (SANTOS, 1987, p. 81)

Dessa forma, na dimensão global, a dignidade da pessoa humana demanda muitas vezes a ação de uma organização internacional para ser eficazmente protegida. No âmbito local, a demanda é outra, pois a interação ocorre no cotidiano, face a face. É necessário o efetivo respeito à dignidade de cada pessoa humana nas suas mais diversas singularidades. 0 reconhecimento do outro, do diferente, é o fundamento de uma relação de hospitalidade e também um fator essencial para criação da identidade que, para ser construída, necessita do diálogo com um outro diferente de mim mesmo e que, antes de tudo, reconheça-me enquanto interlocutor (TAYLOR, 1992).

0 exercício de respeito aos direitos humanos no plano local não se dá no reconhecimento daquele que nos é próximo, semelhante, conhecido e, portanto, a priori respeitado, mas sim diante do outro, do diferente de nós, do diverso, uma vez que:

[...] aceitar a diversidade cultural não é um ato de tolerância para com o outro, distinto de mim ou da minha comunidade, mas o reconhecimento desse outro (pes- 
soal e comunitário) como realidade plena, contraditória, como portador de saber, de conhecimentos e práticas por meio das quais ele é e tenta ser plenamente. (COLL, 2006, p. 98).

0 direito a mediação possibilita que as pessoas envolvidas nas situações conflituosas resolvam seus problemas, negociando as suas diferenças para chegar a um ponto. Ajudar as partes a terem uma capacidade decisória viável para conseguir uma solução onde ambos possam aceitar as diferenças de percepção. A ideia não é o mediador impor uma mudança de comportamento e sim gerar uma reflexão onde as partes busquem os caminhos, onde o outro possa se colocar no lugar do outro e a parti de aí se perceberem como pessoas e portadoras de direitos iguais, mas acima de tudo se perceberem como pessoas que possuem diferenças e essas diferenças tem que ser respeitadas e valorizadas.

A conquista de direitos, ao longo da história, só acontece com a participação e a luta das pessoas. Em vários momentos foram conquistados direitos, como civis, políticos, sociais, culturais, ambientais, econômicos e outros. Todos esses direitos são universais e para todos, são indivisíveis e não se separam, estão todos relacionados entre si. A utilização da mediação como resolução de conflito é um direito humano. A mediação possibilita estar no meio e ajudar as pessoas resolverem suas situações problemáticas a chegarem numa solução favoráveis para todas as partes envolvidas, por isso, podemos considerar a mediação um direito humano.

\section{MEDIAÇ̃̃O}

A mediação para muitos ainda é vista como algo novo, embora sua prática seja bastante antiga e presente em diferentes tipos de civilizações e culturas. A medição já era amplamente utilizada no século $\mathrm{V}$ a.C. Confúcio, pensador e filósofo chinês, dizia que recorrer à medição seria uma excelente alternativa aos tribunais, pois litígios jurídicos tendem a aumentar a não cooperação entre as partes, além de serem susceptíveis de deixar mágoa. Confúcio sugeriu que as partes em conflito deveriam se reunir com uma terceira pessoa neutra - mediador - para ajudá-los a chegar num acordo (PARKINSON, 2016).

0 termo mediação deriva do latim "medius" que significa "no meio", atualmente a mediação é conhecida como um processo de resolução de conflito,assim, vale ressaltar que, muitos ainda usam como sinônimo de conciliação.Para entender melhor o papel dessas soluções alternativas de resolução de conflitos, vamos ver adiante a diferença de cada uma.

Na mediação, visa-se recuperar o diálogo entre as partes, ou seja, restabelecer a comunicação entre as partes, pois são elas que decidem as técnicas de abordagem do mediador, primeiramente se tenta restaurar o diálogo para que posteriormente o conflito em si possa ser mediado, é preciso que haja a voluntariedade, onde podemos observar na Lei de Mediação (Lei $13.140 / 2015)$ no inciso $V$ do art. $2^{\circ}$, onde o legislador positivou o princípio da autonomia da vontade das partes. Só depois pode se chegar à solução.

De acordo com o Conselho Nacional de Justiça (CNJ), a conciliação é um método utilizado em conflitos mais simples, ou restritos, no qual o terceiro facilitador pode adotar uma posição mais ativa, porém neutra com relação ao conflito e imparcial. É um processo consensual breve, que busca uma efetiva harmonização social e a restauração, dentro dos limites possíveis, da relação social das partes.

As duas técnicas são norteadas por princípios como informalidade, simplicidade, economia processual, celeridade e flexibilidade processual. Os mediadores e conciliadores atuam de acordo com princípios fundamentais, estabelecidos na Resolução 125/2010: confidencialidade, decisão informada, competência, imparcialidade, independência e autonomia, respeito à ordem pública e às leis vigentes, empoderamento e validação.

A mediação é sem dúvida um dos melhores caminhos normais para resolver os conflitos, em alguns países essa prática já vem se desenvolvendo há tempos e o com resultados positivos. Parkinson (2016) 
afirma que na China, com sua população de mais de um bilhão de pessoas, existem cerca de um milhão de mediadores, há mediadores em praticamente todo território chinês e as disputas, sejam elas presentes no seio das famílias, nas comunidades ou nos locais de trabalho, saem resolvidas por meio de mediação.

Os centros Judiciários de Solução de Conflitos e Cidadania (CEJUSCS) é um caminho para se alcançar a pacificação social. Nota-se um processo transformativo que o Poder Judiciário vem enfentando para fazer frente à crescente demanda, surgida com o advento da Constituição Federal da República Federativa do Brasil de 1988, onde no inciso XXXV, do artigo $5^{\circ}$, buscou garantir o acesso dos cidadãos à justiça. Desde então, o Ordenamento Jurídico pátrio vem, gradualmente, criando novos mecanismos para a solução da conflituosidade na sociedade, vislubrando alcançar a tão propalada pacificação social.

Precisa-se destacar, entretanto, que o acesso à justiça garantido pela Carta Magna, é um direito e, não, um dever do cidadão de provocar o Poder Judiciário para debelar todos os conflitos de interesses surgidos das interações entre os indivíduos na sociedade. Estabelecida essa premissa, impõe-se uma mudança de cultura dos sujeitos de direito, objetivando prestigiar os métodos autocompositivos, como a mediação e a conciliação, como meios adequados para se dirimir os conflitos de interesses no Estado Democrático de Direito.

Desse modo, a Resolução 125, do Conselho Nacional de Justiça de 29 de novembro de 2010, a Lei de mediação ( $n^{0} 13.140$, de 26 de junho de 2015) e o Novo Código de Processo Civil ( $n^{0} 13.105$, de 16 de março de 2015) determinaram que os Tribunais de Justiça criassem Centros Judiciários de Solução de Conflitos e Cidadania, unidades do Poder Judiciário responsáveis pela realização das sessões e audiências de conciliação e mediação que estejam a cargo de conciliadores e mediadores, bem como pelo atendimento e orientação ao cidadão, estimulando a autocomposição.

Em face do processo transformativo que vem enfrentando o Poder Judiciário para garantir o acesso à justiça conjugado com o tratamento adequado aos conflitos de interesses postos na sociedade brasileira e, à luz da Constituição Federal de 1988, o Conselho Nacional de Justiça, com a atribuição que lhe foi outorgada pela Constituição no artigo 103-B, estabeleceu uma Política Nacional de Tratamento Adequado dos Conflitos.

Inicialmente, cria-se uma série de políticas judiciárias baseadas em metas de produtividade e resultados a serem alcançados pelos tribunais de todo país, tendo o espírito da conciliação como um vetor a ser seguido.O Movimento pela Conciliação foi deflagrado pelo CNJ, em 23 de agosto de 2006. No mesmo ano, no dia 8 de dezembro de 2006, foi dedicado à mobilização do Dia Nacional pela conciliação, instituindo-se, também, no ano subsequente, a Semana Nacional de Conciliação de 3 a 8 de dezembro.

Foi editado pelo CNJ, ainda, a Recomendação $n^{0}$ 8, de 27/02/2007, sugerindo aos Tribunais de Justiça, Tribunais Regionais Federais e Tribunais Regionais do Trabalho planejamento e viabilização de atividades conciliatórias, dentre outras recomendações, como por exemplo, continuidade ao Movimento pela Conciliação, planejamento anual, realização de pesquisas na área e definição de metas a serem alcançadas.

Advoga o Conselho Nacional de Justiça a tese de que o direito do cidadão de acesso à Justiça tem de ser de forma justa e adequada:

\begin{abstract}
0 direito de acesso à Justiça, previsto no art. $5^{\circ}, \mathrm{XXXV}$ da Constituição Federal, além da vertente formal perante os órgãos judiciários, implica acesso à ordem jurídica justa. Por isso, cabe ao Poder Judiciário estabelecer política pública de tratamento adequado dos problemas jurídicos e dos conflitos de interesses, que ocorrem em larga e crescente escala na sociedade, de forma a organizar, em âmbito nacional, não somente os serviços prestados nos processos judiciais, como também os que possam sê-lo mediante outros mecanismos de solução de conflitos, em especial dos consensuais, como a mediação e a conciliação. (CNJ, on-line). .
\end{abstract}

Nesse intento, o CNJ editou a Resolução n 125, de 29 de novembro de 2010, com as alterações trazidas pela sua primeira emenda publicada em 31 de janeiro de 2013, instituiu a Política Nacional de tratamento adequado dos conflitos de interesses no âmbito do Judiciário, como forma de garantir a implementação da conciliação 
e a mediação em todo o país, para também contribuir a dirimir os conflitos de interesse na sociedade.

A referida Resolução aponta que cabe ao Poder Judiciário estabelecer políticas públicas voltadas ao tratamento adequado dos conflitos de interesses, que ocorrem na sociedade, de forma que organize, a nível nacional, não somente os serviços prestados nos processos judiciais, mas também os que possam ser resolvidos mediante outros mecanismos de solução de conflitos, notadamente os consensuais, como a mediação e a conciliação. Vale ressaltar que o CNJ, com a publicação da Resolução $n^{0} 125$, visou incentivar à autocomposição de litígios, não só no âmbito do Poder Judiciário, mas em entidades públicas e privadas parceiras, universidade e instituições de ensino.

Na Resolução n 125/2010, do Conselho Nacional de Justiça, foram criados os Núcleos Permanentes de Métodos Consensuais de Solução de Conflitos e a instalação de Centros Judiciários de Solução de Conflitos e Cidadania para atender aos Juízos, Juizados ou Varas com competência nas áreas cível, fazendária, previdenciária, de família ou dos Juizados Especiais Cíveis e Fazendários. Estabeleceram-se prazos de 30 dias da publicação da Resolução para a criação dos Núcleos Permanentes e de quatro a doze meses para os Centros Judiciários, o que não foi cumprido integralmente por alguns tribunais do país.

Ademais, institucionalizou estratégias de implementação de métodos consensuais de composição de conflitos, bem como estabeleceu objetivos a serem alcançados no âmbito do Poder Judiciário, promovidos pelo Conselho Nacional de Justiça por meio da Resolução n0 125:

Art. $4^{\circ}$ Compete ao Conselho Nacional de Justiça organizar programa com o objetivo de promover ações de incentivo à autocomposição de litígios e à pacificação social por meio da conciliação e da mediação.

Art. $5^{\circ} \mathrm{O}$ programa será implementado com a participação de rede constituída por todos os órgãos do Poder Judiciário e por entidades públicas e privadas parceiras, inclusive universidades e instituições de ensino. Art. $6^{\circ}$ Para desenvolvimento dessa rede, caberá ao CNJ: I - estabelecer diretrizes para implementação da política pública de tratamento adequado de conflitos a serem observadas pelos Tribunais;

II - desenvolver conteúdo programático mínimo e ações voltadas à capacitação em métodos consensuais de solução de conflitos, para magistrados da Justiça Estadual e da Justiça Federal, servidores, mediadores, conciliadores e demais facilitadores da solução consensual de controvérsias, ressalvada a competência da Escola Nacional de Formação e Aperfeiçoamento de Magistrados - ENFAM;

III - providenciar que as atividades relacionadas à conciliação, mediação e outros métodos consensuais de solução de conflitos sejam consideradas nas promoções e remoções de magistrados pelo critério do merecimento;

IV - regulamentar, em código de ética, a atuação dos conciliadores, mediadores e demais facilitadores da solução consensual de controvérsias;

V - buscar a cooperação dos órgãos públicos competentes e das instituições públicas e privadas da área de ensino, para a criação de disciplinas que propiciem o surgimento da cultura da solução pacífica dos conflitos, bem como que, nas Escolas de Magistratura, haja módulo voltado aos métodos consensuais de solução de conflitos, no curso de iniciação funcional e no curso de aperfeiçoamento;

VI - estabelecer interlocução com a Ordem dos Advogados do Brasil, Defensorias Públicas, Procuradorias e Ministério Público, estimulando sua participação nos Centros Judiciários de Solução de Conflitos e Cidadania e valorizando a atuação na prevenção dos litígios; VII - realizar gestão junto às empresas, públicas e privadas, bem como junto às agências reguladoras de serviços públicos, a fim de implementar práticas autocompositivas e desenvolver acompanhamento estatístico, com a instituição de banco de dados para visualização de resultados, conferindo selo de qualidade; VIII - atuar junto aos entes públicos e grandes litigantes de modo a estimular a autocomposição.

Nota-se, assim, uma preocupação, o engajamento e a criação de uma política pública que determina uma responsabilidade social na atuação do Poder Judiciário, com o objetivo de preservar e restaurar os vínculos existentes entre as pessoas, melhorando e tratando os cidadãos como seres humanos imperfeitos, mas que têm interesses e sentimentos que precisam ser preservados no desempenho do seu papel social. A pacificação social decorrente desta política pública certamente está sendo semeada e, na medida em que, são conciliadas, as partes começam a acreditar no sistema de justiça e a se responsabilizar pelas escolhas feitas. 
Além da Resolução 125/2010, o Conselho Nacional de Justiça também publicou a resolução $n^{0}$ 50/2014 para estimular e apoiar os tribunais na adoção das técnicas consensuais de resolução de conflitos.

Outrossim, foram aprovadas no Congresso $\mathrm{Na}$ cional e Sancionadas pela Presidente da República Federativa do Brasil a tão esperada Lei de mediação, $n^{0} 13.140$, de 26 de junho de 2015, que entrou em vigor em 26 de dezembro de 2015 e o Novo Código de Processo Civil, Lei no 13.105, de 16 de março de 2015, que entrou em vigor no dia 17 março de 2016, impondo aos Tribunais de Justiça a criação de Centros Judiciários de Solução de Conflitos e Cidadania (CEJUSCS), unidades do Poder Judiciário responsáveis pela realização das sessões e audiências de conciliação e mediação que estejam a cargo de conciliadores e mediadores, bem como pelo atendimento e orientação ao cidadão, estimulando a autocomposição.

Com base na Resolução $n^{0} 125$, do Conselho Nacional de Justiça, os Núcleos Permanentes terão a atribuição de instalar os Centros Judiciários de Solução de Conflitos e Cidadania, promovendo o desenvolvimento da política judiciária de tratamento adequado dos conflitos de interesses, cuidando do planejamento, implementação, manutenção e aperfeiçoamento das atividades voltadas ao cumprimento da política nacional acima referida e suas metas, atuando na interlocução com os tribunais do país, órgãos e instituições integrantes da rede de cooperação instituída pelo CNJ.

Ademais, os Núcleos Permanentes dos Tribunais do país deverão incentivar ou promover a capacitação, treinamento e atualização permanente de magistrados, servidores, conciliadores e mediadores quanto aos métodos autocompositivos de solução de conflitos de interesse, cadastramento de conciliadores e mediadores, firmar convênios e parcerias com entes públicos ou privados para capacitação e promoção de cursos, promover, ainda, programas de mediação comunitária, podendo também centralizar e estimular programas de mediação penal ou qualquer outro processo restaurativo nos termos do art. 73 , da Lei 9.099/95 e, dos artigos 112 e 116 da Lei 8.069, desde que respeitados os princípios básicos e processos restaurativos previstos na resolução 2.002/12, do Consetho Econômico e Social da Organização das Nações Unidas e a participação do titular da ação penal em todos os atos (PAUMARTTEN, 2015, p.178-179).

Os CEJUSC são unidades do Poder Judiciário, criados pelos Tribunais, seguindo a recomendação da Resolução no 125/2010 do Conselho Nacional de Justiça e a determinação contida na Lei de mediação, no 13.140, de 26 de junho de 2015e o Novo Código de Processo Civil, Lei no 13.105, de 16 de março de 2015.

Os CEJUSCS podem ser criados para atender aos Juízos, Juizados ou Varas com competência nas áreas cível, fazendária, previdenciária, de família ou dos juizados especiais cíveis e fazendários, sendo responsáveis pela realização de sessões e audiências de conciliação e mediação, para o tratamento de conflitos em processos já ajuizados, incidentalmente (processos em que o cidadão por meio de advogado constituído já deu entrada na demanda no Poder Judiciário), ou em fase pré-processual (nos casos em que não existe ainda processo na justiça), ademais, são responsáveis pelo atendimento e orientação ao cidadão.

Vale destacar que o setor do CEJUSC, tem o objetivo de orientar o cidadão sobre o melhor método para resolução do seu conflito, nesta toada revela-se que o Poder Judiciário passa a ser dotado de diversas formas possíveis de resolução do conflito de interesses do jurisdicionado, como por exemplo, a conciliação, a mediação e a jurisdição, tornando-se um verdadeiro Tribunal com múltiplas portas, onde o cidadão poderá acionar o meio mais adequado para tentar solucionar o seu conflito.

Os Centros Judiciários de Solução de Conflito e Cidadania poderão ser organizados por áreas de atuação, como: centros de conciliação de juizados especiais, família, empresarial, consumo, tributário, juntamente como os setores de cidadania, serão facultativamente instalados nos locais onde exista mais de um Juízo, Juizado ou Vara judicial com pelo menos uma das competências atribuídas pela supracitada Resolução do CNJ, e será obrigatória a instalação dos CEJUSCS nos locais com mais de cinco unidades judiciais (PAUMARTTEN, 2015, p. 182-183). 
No CEJUSC haverá um juiz coordenador e, se necessário, um adjunto, aos quais caberão a sua administração, bem como a supervisão dos serviços dos conciliadores e mediadores, assim como serão responsáveis pela homologação dos acordos firmados pelas partes.

Registre-se, ainda, que os servidores públicos que atuarem nos Centros Judiciários deverão dedicar-se exclusivamente aos serviços do Centro, devendo ser capacitados em métodos consensuais de solução de conflitos, consoante estabelecido pelo Conselho $\mathrm{Na}$ cional de Justiça.

No Tribunal de Justiça do Estado de Sergipe (TJSE) foi criado por meio da Resolução n⿳ 35 , de 12 de dezembro de 2012, os CEJUSC, disciplinando que são unidades destinadas precipuamente à realização de sessões e audiências de mediação e conciliação, estabelecendo que as atividades do CEJUSC compreendem a autocomposição processual, pré-processual e 0 setor de cidadania.

\section{CONSIDERAÇÕES FINAIS}

Com as exposições feitas, pode-se concluir a importância da resolução de conflito por meio da mediação como direito humano e acesso à justiça. $A$ mediação é um breve processo que tem como objetivo melhorar a comunicação e ajudar as partes decidirem suas conclusões respeitando os direitos fundamentais de ambos.

Desse modo, os CEJUSC, foram pensados e criados para efetivar a Política Nacional de pacificação social por meio dos métodos adequados de resolução de conflito, objetivando uma mudança de cultura na sociedade, possibilitando a transição do paradigma litigioso, da competição, do perde-ganha para uma cultura de cooperação, de pacificação social e, consensual, onde os cidadãos sejam os protagonistas das suas decisões e responsáveis pelas escolhas feitas, tudo isso sendo chancelado pelo Poder Judiciário, a fim de se alcançar a tão sonhada pacificação social.
Contudo, a Constituição Federativa do Brasil de 1988, acredita no poder judiciário como instância última de proteção aos direitos fundamentais. Garantindo-o aos cidadãos acesso à justiça visando garantir proteção e amparo aos seus direitos.

\section{REFERÊNCIAS}

CALMON, Perônio. Fundamentos da mediação e da

conciliação. Rio de Janeiro: Editora Forense, 2007.

CAPPELLETTI, Mauro. Acesso à justiça. Tradução de Ellen Gracie Northfleet. Porto Alegre, Fabies, 1988.

CASTILHO, Ricardo. Direitos humanos. São Paulo: Saraiva, 2011.

CNJ - CONSELHO NACIONAL DE JUESTIÇA.

Conciliação e mediação. Disponível em: <http:// www.cnj.jus.br/programas-e-acoes/conciliacaomediacao/movimento-conciliacao-mediacao>. Acesso em: 18 maio 2016.

GABBAY, Daniela Monteiro. Mediação \& judiciário no Brasil e nos EUA. Brasília: Gazeta Juridica, 2013.

GONÇALVES, Luciana A. Machado da Silva.

Mediação de conflitos. São Paulo. Atlas, 2013.

GUERRA, Sidney. Direitos humanos: curso

elementar. São Paulo. Saraiva, 2013.

MOORE, Christopher W. 0 processo de mediação. Tradução de Magda França Lopes. Porto Alegre: Artmed, 1998.

MORAES, Alexandre de. Direitos humanos

fundamentais: teoria geral. 10.ed. São Paulo: Atlas, 2013.

PARKINSON, Lisa. Mediação familiar. Belo

Horizonte: Del Rei, 2016. 
PAUMGARTTEN, Michele Pedrosa. Novo processo civil brasileiro. Curitiba: Juruá Editora, 2015.
REVISTA Brasileira de Segurança Pública, Ano 1, 2.ed., 2007
Data da submissão: 25 de Junho de 2017

Avaliado em: 27 de Julho de 2017 (Avaliador A)

Avaliado em: 22 de Agosto de 2017 (Avaliador B)

Aceito em: 23 de Agosto de 2017
1. Assistente Social; Bacharel em Direito; Mestranda em Segurança Pública Justiça e Cidadania pela Universidade Federal da Bahia -UFBA; Bolsista da Fundação de Amparo à Pesquisa do Estado da Bahia - FAPESB. E-mail: natydalto.social@gmail.com 